\title{
Endonasal endoscopic assisted extracorporeal septoplasty in aesthetic reconstruction of crooked nose
}

\begin{abstract}
Objectives: To describe the technique of endonasal endoscopic assisted extracorporeal septoplasty (ECS)/septorhinoplasty and its comparison to ECS/septorhinoplasty via open approach in crooked nose.

Methods: This is a prospective comparative study was conducted on 60 patients suffering from crooked nose and septal deviation of different etiologies between November 2015 and January 2018. Patients were randomly equally divided in 2 groups A and B. Group A underwent endonasal endoscopic assisted ECS/septorhinoplasty and Group B subjected to ECS/septorhinoplasty with open approach. Patient satisfaction was assessed using subjective evaluation of the nasal patency by Nasal Obstruction Symptom Evaluation (NOSE) scale. Anthropometric changes were assessed from preoperative and postoperative facial photographs.

Results: The ECS through endonasal endoscopic assisted approach and in open septorhinoplasty techniques proved to be functionally effective and obtained reasonable straight nasal septum and aesthetic outcome at follow-up in all cases included in the current study. In group A: 24 patients $(89 \%)$ were satisfied with the cosmetic outcome, and all 23 patients with moderate to severe nasal obstruction were satisfied with the postoperative improved nasal breathing.

Conclusion: The technique of ECS through endonasal endoscopic assisted approach provided the structural support without destabilizing the keystone area. Sutures the replanted quadrangular cartilage to the fibrous tissue in the area of the nasal spine under direct endoscopic visualization was easy to perform and effective fixation technique. The present study had some limitations. The study involved a relatively small number of patients, a relatively short follow-up period and an ambiguous indication for ECS.
\end{abstract}

Volume 10 Issue 2 - 2018

\author{
Mohamed O El-Banhawy, Ibrahim A Abd \\ Elshafy, Adel T Atala, Hossam A Omar, Omar \\ A El-Banhawy \\ Department of ENT, Faculty of Medicine, Menoufia University, \\ Egypt
}

Correspondence: Mohamed Omar El-Banhawy, ENT Department, Faculty of Medicine, Menoufia University, Shebin El-Kom, Menoufia, Egypt, Postal Code 325I I, Fax 04738669I6, Email Ibrahim_ent@yahoo.com

Received: February 19, 2018 | Published: March 27, 2018

\section{Introduction}

The term "crooked nose" is commonly used for all of the clinical conditions involving deviation of the nasal pyramid from the median line. In these cases, it can appear vaguely $\mathrm{C}$-shaped or S-shaped or wholly displaced to one side or the other. The consequences for the patient are severe in both functional and aesthetic terms, as great difficulty in nasal respiration is always combined with unsightliness that cannot be hidden. ${ }^{1}$

Septal surgery plays a central role in the successful management of the externally deviated nose. Septal surgery procedures are among the most frequently performed otorhinolaryngological procedures which might be very challenging for the surgeon. Classic septal surgery procedures and septorhinoplasty techniques are not usually capable of reliably correcting severe nasal septal deformities. Quite often the deviation of the external nose persists even after performing septal surgery. Each surgical procedure has its limitations and cannot deal with all the variants of the deformities of the nasal septum. ${ }^{2}$

Extracorporeal septoplasty is a newer, rapidly evolving technique for correction of the severely deviated caudal septum. It is the process where in the entire cartilaginous septum is removed, straightened, reinserted, and secured in the nose. It was first reported by Gubisch. ${ }^{3}$ He described 2 areas of fixation to secure the newly reconstructed septum back into the native nose. The first area of fixation is the caudal end of the nasal bones, where the cephalic dorsal septum is reattached. He accomplished this by suturing the reconstructed septum to the upper lateral cartilage or by placing a transcutaneous U-suture. The second point of fixation is the maxillary crest, where the posterior septal angle is reattached. He accomplished this by drilling a hole through the nasal spine and suturing the newly reconstructed neocaudal septum down to the maxillary crest. $^{3}$

\section{Patients and methods}

This is a prospective comparative study that was conducted on sixty patients suffering from crooked nose and septal deviation of different etiologies attending the outpatient clinic, ENT department, Menufia university hospitals and in our private centres in Egypt, in the period between November 2015 and January 2018.

The study was approved by the scientific and ethical committee of our institution.

\section{Inclusion criteria}

Patients with age more than 18 and less than 50 years of both sexes with crooked nose and septal deviation were included in the study.

\section{Exclusion criteria}

i. Patients aged less than 18 years and greater than 50 years.

ii. Patients with coexisting debilitating diseases, major systemic disease or facial asymmetry. 
iii. Patients with concomitant nasal or paranasal sinus pathology.

iv. Patients with active upper respiratory tract infections preceding two weeks of surgery.

Informed consent was taken from all patients, explaining the procedure, benefits, possible complications and importance of regular follow up postoperatively.

Patients of this study were randomly equally divided in 2 groups:

Group A: subjected to endonasal endoscopic assisted extracorporeal septoplasty/septorhinoplasty

Group B: subjected to extracorporeal septoplasty/septorhinoplasty with open approach

\section{Preoperative assessment}

A detailed and comprehensive otorhinolaryngological evaluation of each patient was performed as described in the the study design using subjective evaluation of the nasal patency by mean of Nasal Obstruction Symptom Evaluation (NOSE) scale. ${ }^{4}$ Other associated symptoms including history of trauma, headache, epistaxis, allergic symptoms: sneezing, itching and rhinorrhea were documented.

Septal deviation was grouped according to the preoperative evaluation to septal dislocation and deviation. Types of septal deviations were mild (one-third reduction of the nasal cavity), moderate (half reduction), and severe (two-thirds reduction). To document the state of the nose and septum for the current study we used the examination sheet prescribed by Tebbetts, $2007 .{ }^{4}$

\section{Preoperative photography}

Four aspect photography documentation were obtained from the patients in all cases: frontal, Basal and lateral (right \& left) views.

\section{Operative procedures}

\section{Group A: It included 30 patients subjected to endonasal endoscopic assisted extracorporeal septoplasty/septorhinoplasty}

Position of the patient: The procedure was performed under general anesthesia in supine position with head elevated about 15 degrees and face towards the surgeon. The patient was draped and prepared as for standard endoscopic sinus surgery Endoscopic septal surgery was performed with video assistance; The nasal cavity was examined endoscopically and the site and severity of the deviation or septal spurs was noted, Lignocaine 1\% and adrenaline 1:100000 is injected subperichondrially along the septum.

All instruments used were non-powered instrumentation (e.g. dissectors, suctions etc.) and the same like that used in the traditional septoplasty. An incision was made at the caudal end of the nasal septum (hemitransfixation). The incision was made on the concave side of the septum to expose the abnormality at the bony cartilaginous junction. The initial mucoperichondrial flap was elevated using Freer's elevator. Further elevation was done using $0^{0}$ rigid nasal endoscope $(4 \mathrm{~mm})$, keeping the tip of the endoscope between the mucoperichondrial flap and the septal cartilage. Flap elevation in the correct cleavage plane to minimize the bleeding. Exposure was limited to the target area.
The flap elevated was limited as it was raised from over the most deviated portion of the nasal septum, without disturbing the rest of nasal septum. Septal cartilage was incised parallel but posterior to the flap incision and caudal to the deviation. Deviated portions of bone from the vomer or perpendicular plate of the ethmoid were removed as necessary. This step was followed by bilateral extramucosal dissection of the junction of the border between the caudal septum and upper lateral cartilage to preserve an intact mucosal cover. The upper lateral cartilages were incised bilaterally at their junction with the septum after extramucosal dissection. This maneuver made the nasal septum more flexible and made mucosal dissection easier and more accurate.

The entire septal cartilage was dislocated from its suture line with maxillary and or palatine crests. If there was a bony septal spur at this area a paramedian osteotomies were used to free the nasal septum along its inferior border.

The complete cartilaginous and bony septum was then excised along its superior border except for the remaining few millimeters of the dorsal strip at the keystone area and removed in 1 piece if possible. $^{5}$

Several technical options were used to create a straight septal plate which needs usually the dimensions of $30 \mathrm{~mm}$. in horizontal and 18 $20 \mathrm{~mm}$. in vertical extension. The ideal reconstructed plate would be as large as possible, with stable upper and anterior borders. Redundant cartilage and fracture lines can be excised and sutured together to provide a stable reconstructed nasal septum. Partial-thickness releasing incisions on the concave side of the cartilage with a knife may straighten the bent cartilage (Figure 1). Smoothing the cartilage and bone with a sharp drill may be necessary. If the cartilage was straight but soft and unstable, 2 options exist to stabilize it. Smoothly filed pieces of the lamina perpendicularis of the ethmoid bone could be sutured to the cartilaginous septum (Figure 2).
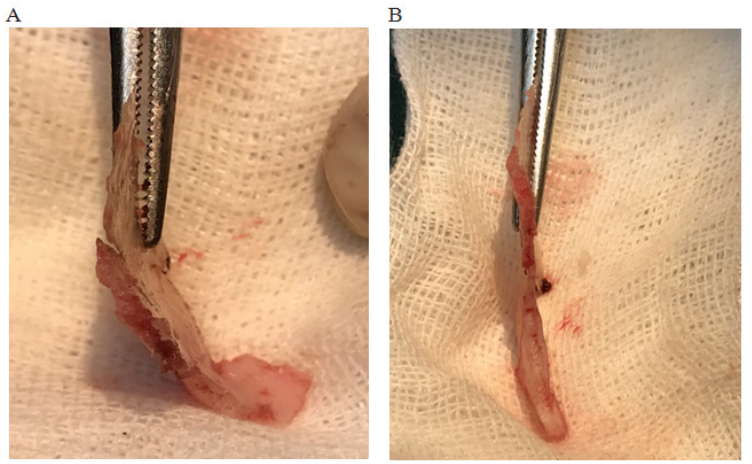

Figure I Twenty-year-old man with a deviated nose after trauma.A, Removed nasal septum demonstrating deviated cartilage. B, Straight septum after excision of some cartilage and partial thickness releasing incisions on the concave side of the cartilage.

In post-traumatic cases with multiple fractures sites and cartilaginous fragments healed in the wrong position, it was often possible to dissect and preserve many pieces of straightened cartilage. These could be used to construct a neoseptum (Figure 3).

The neoseptum was then replanted between the two perichondrial and subperiosteal layers. Stable fixation of the replanted septum 
was essential for permanent aesthetic and functional success. The new upper septum border was positioned at the height of the lateral cartilage, temporarily fixed with needles if necessary, and reconnected to the lateral cartilages using 2 sutures (Figure 4) use of a U-shaped
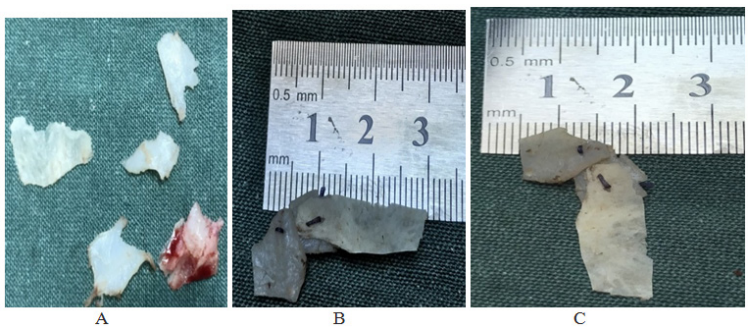

Figure 2 A, The removed nasal septum demonstrates cartilage that is thin, weak, and without support. A thin piece of the perpendicular plate of the ethmoid was harvested for stabilization of the cartilage. B and C, Reconstructed septum as cartilage-bone sandwich in dorsal L-strut cutting and suture technique, with the dimension of $30 \mathrm{~mm}$. in horizontal and 18 $\mathrm{mm}$. in vertical extension. Multiple small holes have been drilled in the lamina perpendicularis to allow suture placement and tissue in growth.

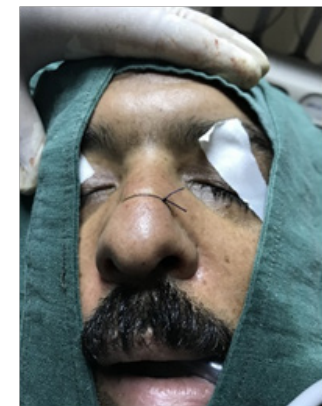

Figure 4 Possible ways of securing the replanted nasal septum, Fixation on the lateral cartilage with polydioxanone suture.

The hemitransfixion incision was closed. A quilting suture was placed in the anterior septum, leading from caudal to cranial and back, to approximate the nasal mucosa, prevent dead space and hematoma formation, and further stabilize the replanted septum. Silicone nasal septum splints were inserted and Meroce nasal packs were applied.

Group B: Thirty patients with crooked nose and septal deviation that caused nasal deformity and air way obstruction were treated with extracorporeal septo-rhinoplasty through open approach. All the cases were done under general anesthesia. The procedure was carried out as described by Gubisch (A).

Post-operatively patients were put on antibiotics at least for a week, along with analgesics and decongestants. Nasal packs were removed 48 hours after the surgery. Saline nasal douching was advised for a week. Patients were followed up on seventh day and then monthly up to six months. At each follow up visit, subjective and objective assessment was done. Subjective assessment was done by asking about nasal obstruction, headache, nasal discharge, hyposmia, post nasal discharge. Objective assessment was done clinical and with diagnostic nasal endoscopy.

\section{Postoperative assessment}

The patients to be followed up for a minimum period of 6 months to record postoperative symptom improvement rate included surgical complications, revision rate, and the surgeon's subjective suture pattern is recommended to secure the cartilage and allow final modifications of the dorsum without cutting the suture if indicated. The replanted nasal septum was sutured to the fibrous tissue in the area of the nasal spine under direct endoscopic visualization.
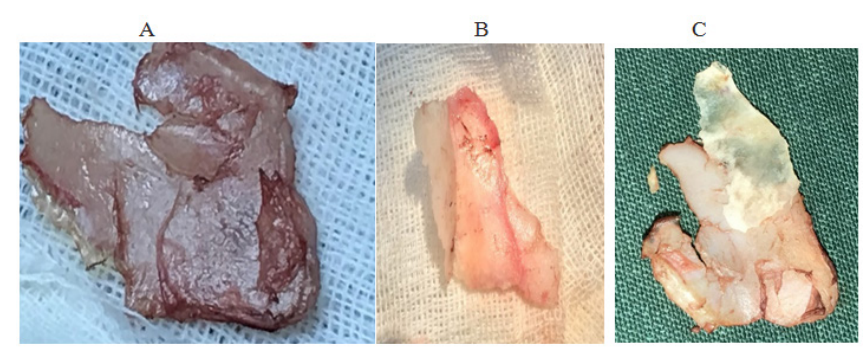

Figure 3 Nineteen-year-old woman with a crooked nose and deviated nasal septum secondary to trauma. $A$, Removed of nasal septum. Fracture lines at sites of cartilage dislocation B, Straight, reconstructed septum after excision of redundant dislocated cartilage. $\mathrm{C}$, The reconstructed straight septal plate before reinsertion.

determination of functional and aesthetic outcomes. Nasal Obstruction Symptom Evaluation (NOSE) was applied postoperatively.

Photography: Postoperative regular follow up photography was conducted for at least two month. Preoperative and postoperative photographs were studied to evaluate surgical outcome (Figure 5).

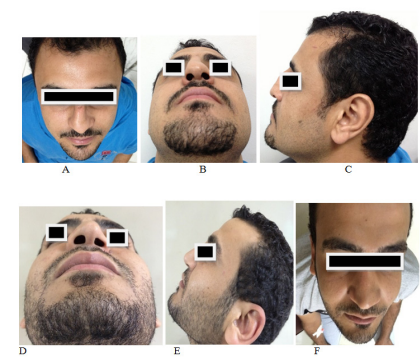

Figure 5 Male patient 28 years old with history of trauma. (A), (B) \& (C) are the preoperative pictures. (D), (E) \& (F) are one year post-operatively after endoscopic assisted extracorporeal septo-rhinoplasty.

\section{Assessment of outcomes and complications}

Assessment of deviation improvement was based on comparisons between the preoperative photograph and the postoperative photograph at the final follow-up. According to this, Outcomes were classified as: $0=$ No change, $1=$ Fair, $2=$ good and $3=$ Excellent.

Subjective analysis for aesthetic score using Visual Analogue Scale (VAS) for their symptom. Aesthetic scores are plotted from 0 to 4 for subjective improvement; where: $0=$ no improvement, $1=$ mild improvement, 2 = moderate improvement, 3 =good improvement, 4 $=$ excellent improvement.

Postoperative history was reviewed to assess complications, including postoperative infection, postoperative deformity (e.g., saddling or notching), incomplete correction, recurrence of deviation and loss of tip support or projection.

The results of this study to be analyzed on SPSS Software using "Paired' $t$ ' test". 
The outcomes of surgery were measured. Unpaired $t$ test was used to measure the outcome with respect to nasal patency. Chi square test was used to measure the outcome with respect to other signs, symptoms and complications.

\section{Results}

This study was conducted on sixty patients suffering from crooked nose and septal deviation of different etiologies attending the outpatient clinics of ENT department, Menufia university hospitals and Prof. Omar El-Banhawy ENT Center, Mansoura, Dakhlia in Egypt during the period between November 2015 and January 2018. Patients of this study are randomly divided in 2 groups A and B:

\section{Group A}

Table I Main rhinologic complains of patients in group $A$

\begin{tabular}{lll}
\hline & Frequency $(\mathbf{n = 3 0})$ & Percentage \\
\hline Sex & 23 & $76.7 \%$ \\
Male & 7 & $23.3 \%$ \\
Female & & \\
Main complaint & & \\
Cosmetic & 21 & $70 \%$ \\
Disfiguremen & 10 & $33.3 \%$ \\
Headache & 17 & $56.7 \%$ \\
Nasal obstruction & 1 & $3.3 \%$ \\
Epistaxis & 6 & $20 \%$ \\
Allergic & & \\
History of trauma & & \\
There was trauma & 22 & $73.3 \%$ \\
No trauma & 8 & $26.7 \%$ \\
& & \\
Septum & & $66.7 \%$ \\
Deviated & 20 & $33.3 \%$ \\
Displaced & 10 & \\
\hline
\end{tabular}

This group included 30 patients with crooked nose subjected to endonasal endoscopic assisted extracorporeal septoplasty/ septorhinoplasty. This group included 23 males and 7 females with age ranges from 18 to 50 years [Mean age $=26.9$ with standard deviation=6.3].

\section{Preoperative assessment}

Those patients had different complaints. Twenty one patients were complaining of cosmetic disfigurement (70 \%), seventeen with nasal obstruction $(56.7 \%)$, ten with headache $(33.3 \%)$, six with allergic symptoms $(20 \%)$ and one patient $(3.3 \%)$ with mild infrequent epistaxis. After history taking and examination, 22 patients $(73.3 \%)$ showed history of trauma, 20 patients $(66.6 \%)$ with deviated septum and 10 patients $(33.3 \%)$ showed displaced septum (Table 1).

\section{Post operatively}

The postoperative VAS-Cosmetic results showed that one patient (3.3\%) showed mild improvement, eight patients $(26.7 \%)$ were moderately improved, 12 patients showed good improvement (40\%) and nine patients ( $30 \%)$ with excellent improvement. By examination, two $(6.6 \%)$ patients showed mild nasal septum deviation not causing nasal obstruction and 28 patients $(93.3 \%)$ showed acceptable central septum.

There were two patients $(6.6 \%)$ developed nasal synechia and one patient $(3.3 \%)$ with subcongunctival hemorrhage that resolved completely after one week.

On comparison between the preoperative and postoperative photographs there were eight patients $(26.7 \%)$, with fair satisfaction, twelve patients (40\%) with good satisfaction and ten patients $(33.3 \%)$ with excellent satisfaction. On comparison between the results obtained from the photographic assessment and that from patient satisfaction we found that it is statistically highly significant, indicating that patient satisfaction is greater than expected from the photographic assessment (Table 2).

Table 2 Comparison between photographic assessment and patient satisfaction in group A

\begin{tabular}{|c|c|c|c|c|c|c|c|c|}
\hline \multicolumn{9}{|l|}{ Photographs } \\
\hline \multirow[b]{2}{*}{ VAS } & \multirow{2}{*}{$\begin{array}{l}\text { No Change } \\
\mathrm{N}=0 \\
(0 \%) \\
\mathrm{N} \%\end{array}$} & \multicolumn{2}{|c|}{ Fair $\mathrm{N}=8(26.7 \%)$} & \multicolumn{2}{|c|}{$\begin{array}{l}\text { Good } \\
N=12(40 \%)\end{array}$} & \multicolumn{2}{|c|}{$\begin{array}{l}\text { Excellent } \\
\mathrm{N}-=10(33.3 \%)\end{array}$} & \multirow[t]{2}{*}{$P$ value } \\
\hline & & $N$ & $\%$ & N & $\%$ & N & $\%$ & \\
\hline No improvement & - & 0 & - & - & - & - & - & \multirow{4}{*}{$<0.001$} \\
\hline Mild improvement & - & I & 12.5 & - & - & - & - & \\
\hline $\begin{array}{l}\text { Moderate } \\
\text { improvement }\end{array}$ & - & 6 & 75 & 2 & 16.7 & - & - & \\
\hline Good improvement & - & I & 12.5 & 9 & 75 & 2 & 20 & \\
\hline Excellent improvement & - & - & - & I & 8.3 & 8 & 80 & \\
\hline
\end{tabular}




\section{Group B}

Thirty patients with crooked nose and septal deviation that caused nasal deformity and air way obstruction were treated with extracorporeal septo-rhinoplasty through open approach. All the cases were done under general anesthesia. The procedure was carried out as described by Gubisch (A).

Post-operatively patients were put on antibiotics at least for a week, along with analgesics and decongestants. Nasal packs were removed 48 hours after the surgery. Saline nasal douching was advised for a week. Patients were followed up on seventh day and then monthly up to six months. At each follow up visit, subjective and objective assessment was done. Subjective assessment was done by asking about nasal obstruction, headache, nasal discharge, hyposmia, post nasal discharge. Objective assessment was done clinical and with diagnostic nasal endoscopy.

\section{Postoperative assessment}

The patients to be followed up for a minimum period of 6 months to record postoperative symptom improvement rate included surgical complications, revision rate, and the surgeon's subjective determination of functional and aesthetic outcomes. Nasal Obstruction Symptom Evaluation (NOSE) was applied postoperatively.

Photography: Postoperative regular follow up photography was conducted for at least two month. Preoperative and postoperative photographs were studied to evaluate surgical outcome (Figure 5).

\section{Post operativel}

The postoperative VAS-Cosmetic results showed that one patient (3.3\%) showed mild improvement, eight patients $(26.7 \%)$ were moderately improved, 12 patients showed good improvement (40\%) and nine patients (30\%) with excellent improvement. By examination, two $(6.6 \%)$ patients showed mild nasal septum deviation not causing nasal obstruction and 28 patients $(93.3 \%)$ showed acceptable central septum.

There were two patients $(6.6 \%)$ developed nasal synechia and one patient $(3.3 \%)$ with subcongunctival hemorrhage that resolved completely after one week.

On comparison between the preoperative and postoperative photographs there were eight patients $(26.7 \%)$, with fair satisfaction, twelve patients $(40 \%)$ with good satisfaction and ten patients $(33.3 \%)$ with excellent satisfaction. On comparison between the results obtained from the photographic assessment and that from patient satisfaction we found that it is statistically highly significant, indicating that patient satisfaction is greater than expected from the photographic assessment.

\section{Group B:}

This group included 30 patients with crooked nose with deviated nasal septum subjected to extracorporeal septoplasty/septorhinoplasty with open approach. This group included 21 males and 9 females with age ranges from 18 to 50 years [Mean age $=29.1$ with standard deviation $=5.7]$.

\section{Preoperative assessment}

Those patients had different complaints. Twenty patients (66.7\%) were complaining of cosmetic disfigurement, eighteen $(60 \%$ with nasal obstruction, eleven $(36.7 \%)$, with headache six $(20 \%)$ with allergic symptoms and two (6.6\%) patient with mild infrequent epistaxis. After history taking and examination, 20 patients $(66.7 \%)$ showed history of trauma, 22 patients $(73.3 \%)$ with deviated septum and 8 patients (26.7\%) showed displaced septum (Table 3).

Table 3 Main rhinologic complains of patients in group B

\begin{tabular}{lll}
\hline & $\begin{array}{l}\text { Frequency } \\
(\mathbf{n}=\mathbf{3 0})\end{array}$ & Percentage \\
\hline Sex & & \\
Male & 21 & $70 \%$ \\
Female & 9 & $307 \%$ \\
& & \\
Main complaint & & \\
Cosmetic Disfigurement & 20 & $66.7 \%$ \\
Headache & 11 & $36.7 \%$ \\
Nasal obstruction & 18 & $60 \%$ \\
Epistaxis & 2 & $6.6 \%$ \\
Allergic & 6 & $20 \%$ \\
& & \\
History of trauma & & $66.7 \% \%$ \\
There was trauma & 20 & $33.3 \%$ \\
No trauma & 10 & \\
& & \\
Septum & & $26.7 \%$ \\
Deviated & 22 & \\
Displaced & 8 & \\
\hline
\end{tabular}

\section{Post operative assessment}

The postoperative VAS-Cosmetic results showed that one patient (3.3\%) with no improvement, two $(6.6 \%)$ with mild improvement, four were moderately improved (13.3\%), fourteen (46.7 \%) showed good improvement and patients $(30 \%)$ with excellent improvement. By examination, 3 patients showed mild nasal septum deviation (9.9 $\%)$ and 27 (90\%) patients showed acceptable central septum. There were 4 patients developed nasal synechea (13.3\%) and one patient (3.3\%) with subcongunctival hemorrhage

On comparison between the preoperative and postoperative photographs there were two patients $(6.7 \%)$ with 1 '.no change, five patients $(16.7 \%)$ with fair satisfaction, 14 patients $(46.7 \%)$ with good satisfaction and nine patients (30\%) with excellent satisfaction.

On comparison between the results obtained from the photographic assessment and that from patient satisfaction we found that it is statistically highly significant, indicating that patient satisfaction is greater than expected from the photographic assessment (Table 4).

On comparison between both groups regarding demographics, the age and sex weren't statistically significant. Furthermore, deviated or crooked nose is more common in males than females and also common in young age group (Table 5). 
Table 4 comparison between photographic assessment and patient satisfaction in group B.

\begin{tabular}{|c|c|c|c|c|c|c|c|c|c|}
\hline \multicolumn{10}{|l|}{ Photographs } \\
\hline \multirow[b]{2}{*}{ VAS } & \multicolumn{2}{|c|}{$\begin{array}{l}\text { No Change } \\
N=2 \\
(6.6 \%)\end{array}$} & \multicolumn{2}{|c|}{ Fair $\mathrm{N}=5$ (16.7\%) } & \multicolumn{2}{|c|}{$\begin{array}{l}\text { Good } \\
N=14(46.7 \%)\end{array}$} & \multicolumn{2}{|c|}{$\begin{array}{l}\text { Excellent } \\
\mathrm{N}-=9(30 \%)\end{array}$} & \multirow[t]{2}{*}{$P$ value } \\
\hline & $\mathrm{N} \%$ & & $\mathrm{~N}$ & $\%$ & $\mathrm{~N}$ & $\%$ & $N$ & $\%$ & \\
\hline No improvement & I & 50 & 0 & - & - & - & - & - & \multirow{5}{*}{$<0.001$} \\
\hline Mild improvement & I & 50 & 1 & 20 & - & - & - & - & \\
\hline $\begin{array}{l}\text { Moderate } \\
\text { Improvement }\end{array}$ & - & - & 3 & 60 & 1 & 7.1 & - & - & \\
\hline Good improvement & - & - & I & 20 & 12 & 85.8 & I & 11.1 & \\
\hline Excellent improvement & - & - & - & - & 1 & 7.1 & 8 & 88.9 & \\
\hline
\end{tabular}

Table 5 Comparison between both groups regarding demographics is statistically insignificant.

\begin{tabular}{llll}
\hline & Group A $(\mathbf{n}=\mathbf{3 0})$ & Group B $(\mathbf{n}=\mathbf{3 0})$ & P Value \\
\hline $\begin{array}{l}\text { Sex } n, \% \\
\text { Male }\end{array}$ & 23 & 21 & 0.6 \\
Female & 7 & 9 & \\
Age (years) Mean \pm SD & $25.9 \pm 9.3$ & $26.7 \pm 9.3$ & 0.2 \\
\hline
\end{tabular}

*: Fisher's exact test, \#: independent sample t-test

On comparison between both groups regarding VAS cosmetic results, we found that the results were not statistically significant (P value $=0.2$ ). Although that the postoperative VAS-Cosmetic results of good and excellent improvement in group (A) was $73.3 \%$ compared to $76.7 \%$ in group (B).

Also on comparison between both groups regarding the assessment of preoperative and postoperative photography, we found that the results were not statistically significant $(\mathrm{P}$ value $=0.5$ ). Although that the patients showed good and excellent satisfaction were $73.3 \% \%$ in group (A) compared to $76.7 \%$ in group (B) (Table 6).

Table 6 Comparison between both groups regarding VAS \& photograph

\begin{tabular}{ccccc}
\hline Group A & \multicolumn{2}{c}{ Group B } & P \\
& value \\
\hline N & $\%$ & N & $\%$ &
\end{tabular}

VAS

No improvement

Mild improvement

Moderate Improvement

Good improvement

Excellent improvement

$\begin{array}{llll}- & - & 1 & 3.3 \\ 1 & 3.3 & 2 & 6.6 \\ 8 & 26.7 & 4 & 13.3 \\ 12 & 40 & 14 & 46.7 \\ 9 & 30 & 9 & 30\end{array}$

Photography

No change

Fair

Good

Excellent
0.2

46.7

0.4

$\begin{array}{llll}- & - & 2 & 6.6 \\ 8 & 26.7 & 5 & 16.7 \\ 12 & 40 & 14 & 46.7 \\ 10 & 33.3 & 9 & 30\end{array}$

The following are examples of patients whose results considered good and excellent (Figure 6-8).
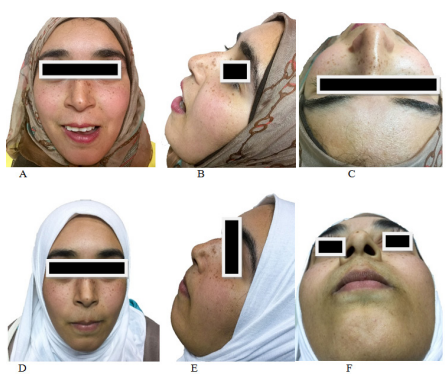

Figure 6 Female patient 24 years old with no history of trauma. (A), (B) \& (C) are the preoperative pictures. (D), (E) \& $(F)$ are the post-operative pictures with open approach.
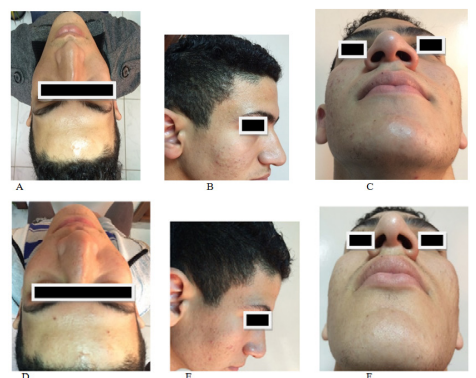

Figure 7 Male patient 20 years old athletic with history of trauma. (A), (B) \& (C) are the preoperative pictures. (D), (E) \& (F) are the post-operative pictures with endoscopic assisted approach. 


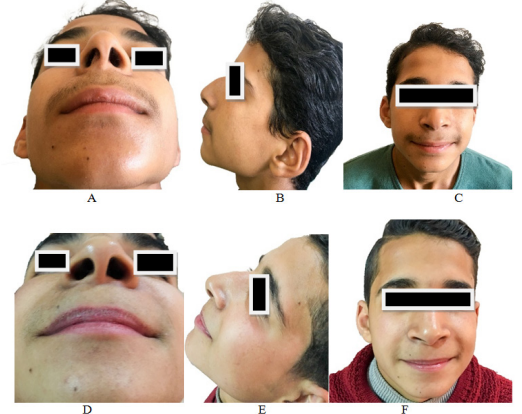

Figure 8 Male patient 18 years old athletic with history of trauma. (A), (B) \& (C) are the preoperative pictures. (D), (E) \& (F) are the post-operative pictures with endoscopic assisted approach.

\section{Discussion}

An ideal surgical correction of the nasal septum should satisfy the following criteria : (a) should relieve the nasal obstruction; (b) should be conservative;(c) should not produce iatrogenic deformity; (d) should not compromise the osteomeatal complex and (e) must have the scope for a revision surgery, if required later. The traditional surgeries of the nasal septum improve the nasal airway but do not fulfill the above mentioned criteria in most instances. The reasons being, poor visualization, relative inaccessibility, poor illumination, difficulty in evaluation of the exact pathology, need for nasal packing, unnecessary manipulation, resection and overexposure of the septal framework reducing the scope for a revision surgery, if required later. ${ }^{3}$

As early as the 1950 s, King \& Ashley ${ }^{6}$ suggested that the complete septum should be removed and corrected in such cases. Extracorporeal septoplasty is a surgical technique for correcting a severely deviated septum. In extracorporeal septoplasty, the whole septum is removed, reshaped, and then re-implanted back into its original site. In the past 20 years, the functional and aesthetic results have been evaluated constantly and the technique has been advocated for correcting a severely deviated septum. ${ }^{7,8}$

In the current study extracorporeal septoplasty surgery several technical options were used to create a straight septal plate and/or even a septal framework which needs usually the dimensions of 30 $\mathrm{mm}$. in horizontal and $18-20 \mathrm{~mm}$. in vertical extension. The ideal reconstructed plate was large as possible, with stable upper and anterior borders. Redundant cartilage and fracture lines were excised and sutured together to provide a stable reconstructed nasal septum.

Song et al., ${ }^{9}$ used similar techniques such as scoring and thinning for straightening or repositioning the deviated dorsal septum. Sutures, bone or cartilage battens were used for maintaining these changes. Although these techniques are relatively noninvasive and quick, sometimes they become not appropriate to correct severe cartilaginous deviation because they can't counter the cartilage memory or the inherent tensile forces that can cause later on recurrence of the deviation. For that reason extracorporeal septoplasty was invented not only for correction of the severely deviated caudal septum but also to overcome the cartilage memory.

In earlier study, it was reported about aesthetic complications in up to 11 percent of cases after extracorporeal septoplasty. ${ }^{10}$ Several surgeons still regard extracorporeal septoplasty as a procedure bearing unacceptable risk because of thorough skeletal destabilization. The critical and most important part in extracorporeal septoplasty is reimplantation of the neoseptum. This requires reattachment of both the cephalic dorsal neoseptum and the caudal part to the anterior nasal spine. ${ }^{10}$

For fixing the neoseptum it was advocated to suture septal cartilage with U-shaped sutures between the upper lateral cartilages, achoring with transseptal multiple mattress sutures, and drilling a hole in the anterior nasal spine through which sutures can be done.

In both groups of the current study fixation of the neoseptum to the keystone area (osteocartilaginous junction), to prevent nasal saddling, we used U-shaped transcutaneous sutures between the upper lateral cartilages. There was no failure rate (no nasal saddling) in both groups.

In Group A, suturing the replanted quadrangular cartilage to the fibrous tissue in the area of the nasal spine under direct endoscopic visualization was easy to perform as effective fixation technique. There has been no failure rate instead of $6.4 \%$ that was previously reported. In group B, suturing and fixation of the neoseptum to the anterior nasal spine itself were done by drilling a hole to prevent slippage no failure rate also.

Because evaluation of photographs for aesthetic or dorsal irregularities is based mainly on subjective view, we only evaluated complications that inevitably needed surgical revision to increase informative value. Performing these techniques in the patients of the current study over the period of the follow up, we did not observe any complications needing operative revision that were associated.

In 2006, Most ${ }^{11}$ and modified Gubisch's ${ }^{3}$ technique to simplify the reconstruction and decrease the aesthetic complications along the bony and cartilaginous dorsum. Most ${ }^{11}$ described excising almost all of the cartilaginous septum (as Gubisch described), preserving a 1.5$\mathrm{cm}$ dorsal septum remnant. He then sutured the reconstructed septum to whichever side of the dorsal remnant was more concave. Fixation in the area of the posterior septal angle to the nasal spine was performed similarly as described by Gubisch. ${ }^{3}$ Most ${ }^{11}$ achieved functional results that were excellent, and he reported no aesthetic complications.

In an era in which outcomes data are growing increasingly critical, little is known about the complications of extracorporeal septoplasty because only a few articles have published such data. The majority of data regarding complications with this technique are from Gubisch's experience. ${ }^{3}$ Data describing the complications using the modified technique by Most $^{11}$ are limited to only 37 patients in 2006 . Because extracorporeal septoplasty is a newer and evolving technique, it is crucial that more results when published describing its associated complication rates so that safety, efficacy, and outcomes can be more easily determined by a review of the literature.

Bloom et al. ${ }^{12}$ recently published a review article covering a large number of studies about the complications for endonasal septoplasty. The possible complications from a standard endonasal approach include hemorrhage or septal hematoma (6\%-14\%), cerebrospinal fluid leak (rare), infection $(0.048 \%-2.5 \%)$, overcorrection $(2 \%)$, septal perforation $(1 \%-6.7 \%)$, adhesions or synechiae (7\%), hyposmia $(0.3 \%)$, and aesthetic deformities $(4 \%-8 \%)$. All these complications are also possible when performing the extracorporeal technique. 
As mentioned previously, Gubisch ${ }^{3}$ was the first to report his data about complication of extracorporeal septoplasty. He reported a hemorrhage/septal hematoma rate of $0 \%$, an infection rate of less than $1 \%$, a septal perforation rate of less than $1 \%$, and an aesthetic complication rate of $7 \%$ to $11 \%$. Later, Most ${ }^{11}$ reported his complication rate among 37 patients undergoing the modified technique as an astonishing $0 \%$ across the board.

In the current study there was no major complication both groups. In group $\mathrm{A}$ in the current study there were 2 patients developed nasal synechea $(6.6 \%)$ and one patient $(3.3 \%)$ with subcongunctival hemorrhage that resolved completely after one week. Also on comparison between the preoperative and postoperative photographs there were 8 patients with fair improvement $(26.7 \%), 12$ patients $(40 \%)$ with good improvement and 10 patients $(33.3 \%)$ with excellent improvement. On comparison between the results obtained from the photographic assessment and that from patient satisfaction we found that it is statistically highly significant, indicating that patient satisfaction is greater than expected from the photographic assessment.

In group $\mathrm{B}$ there were 4 patients developed nasal synechea $(13.3 \%)$ and one patient (3.3\%) with subcongunctival hemorrhage. On comparison between the preoperative and postoperative photographs there were two patients $(6.7 \%)$ with no improvement, five patients with fair improvement (16.7\%), 14 patients (46.7\%) with good improvement and 9 patients $(30 \%)$ with excellent improvement.

The results of the current study showed that patients in both groups were satisfied with the cosmetic outcome, in postoperative improvement of nasal breathing and low rate of complications. Also the minor complications reported are in agreement with that published previously by Bloom et al., ${ }^{12}$ Gubisch $^{3}$ and Most authors. ${ }^{11}$

The technique of extracorporeal septoplasty through endonasal endoscopic assisted approach provided the structural support without destabilizing the keystone area; moreover, suturing the replanted quadrangular cartilage to the fibrous tissue in the area of the nasal spine under direct endoscopic visualization was easy to perform and effective fixation technique.

This study adds additional information to the literature regarding the risks of traditional septoplasty techniques compared with the more evolved technique of extracorporeal septoplasty.

\section{Limitations}

The present study had some limitations. The study involved a relatively small number of patients, a relatively short follow-up period and an ambiguous indication for extracorporeal septoplasty. We believe that the technique of extracorporeal septal reconstruction using either approach can be recommended even to less experienced rhinosurgeons.

\section{Conclusion}

The extracorporeal septoplasty through endonasal endoscopic assisted approach and open septorhinoplasty techniques proved to be functionally effective at long-term follow-up in all cases of crooked nose and deviated nasal septum included in the current study. Both techniques obtained reasonable straight nasal septum and hence respiratory function and aesthetic outcome. The technique of extracorporeal septoplasty through endonasal endoscopic assisted approach provided the structural support without destabilizing the keystone area; moreover, suturing the replanted quadrangular cartilage to the fibrous tissue in the area of the nasal spine under direct endoscopic visualization was easy to perform and effective fixation technique.

\section{Acknowledgment}

None.

\section{Conflict of interest}

None.

\section{References}

1. Pascali M, Boccieri A, Carinci F, et al. Treatment of the Crooked Nose: The Final Steps to Perfection. J Craniofac Surg. 2017;28(2):372-378.

2. Loyo M, Wang TD. Management of the Deviated Nasal Dorsum. Facial Plast Surg. 2015;31(3):216-227.

3. Gubisch W. Extracorporeal septoplasty for the markedly deviated septum. Arch Facial Plast Surg. 2005;7(4):218-226.

4. Tebbetts J. Primary Rhinoplasty. 2nd edition. Elsevier: Australia; 2007.

5. Gode S, Benzer M, Uslu M, et al. Outcome of In Situ Septoplasty and Extracorporeal Subtotal Septal Reconstruction in crooked noses: A Randomized Self-Controlled Study. Plast Reconstr Surg (1946). 1952;10(2):116-120.

6. King ED, Ashley FL. The correction of the internally and externally deviated nose. Plast Reconstr Surg. 1952;10(2):116.

7. Pons Y, Champagne C, Genestier L, et al. Endoscopic Septoplasty: Tips and pearls. Eur Ann Otorhinolaryngol Head Neck Dis. 2015;132(6):353356.

8. Ross Mobley S, Long J. Extracorporeal Septoplasty: Assessing Functional Outcomes Using the Validated Nasal Obstruction Symptom Evaluation Score over a 3-Year Period. Plast Reconstr Surg. 2016;137(1):151e-163e.

9. Song HM, Kim JS, Lee BJ, et al. Deviated Nose Cartilaginous Dorsum Correction Using a Dorsal L-Strut Cutting and Suture Technique. Laryngoscope. 2008;118(6):981-986.

10. Wilson MA, Mobley SR. Extracorporeal septoplasty: complications and new techniques. Arch Facial Plast Surg. 2011;13(2):85-90.

11. Most SP. Anterior septal reconstruction: outcomes after a modified extracorporeal septoplasty technique. Arch Facial Plast Surg. 2006;8(3):202-207.

12. Bloom JD, Kaplan SE, Bleier BS, et al. Septoplasty complications: avoidance and management. Otolaryngol Clin North Am. 2009; 42(3):463-481. 